\title{
Guidance and application of local colleges and universities to the construction of rural information service
}

\author{
Jiang Chunxu
}

Baicheng Normal University 137000

Keywords: Colleges and universities; rural information; application

\begin{abstract}
With the continuous development of information technology, China urgently needs to comprehensively promote the development of rural informatization, in order to promote the improvement of rural economic level and the quality of rural public services. Local colleges and universities, whether in information technology equipment or information technology personnel, have a strong advantage. Therefore, local colleges and universities can play an important role in rural information construction. The main problem discussed in this paper is what specific ways local colleges and universities should take to assist the development of rural information construction, aiming to analyze the basic situation and existing problems of rural information service construction comprehensively, and to seek the effective guidance means of local colleges and universities to the surrounding rural information construction, and summarize the experience and shortcomings obtained in the specific application link.
\end{abstract}

\section{Provide books, audio and video resources}

Since the 1990s, all countries have successively entered into the development trend of comprehensive Internet. With the continuous development of science and technology, Internet media has gradually replaced the status of traditional mass media, including government-issued information on benefiting farmers, agricultural information and other information are more relying on the Internet to publish. According to statistics, there are over 700 million Internet users in China, but most of them use mobile phones to surf the Internet with main purpose of entertainment mainly. Especially in rural areas, most of the rural population has a low level of media literacy and cannot make full use of the Internet to obtain agricultural information, and a considerable part of the rural population does not have good access to the Internet. Although there is a lot of information about agriculture, rural areas and farmers in the network media, most farmers lack the ability to collect, discriminate and collect information. Therefore, when facing the huge amount of information on the Internet, they are often at a loss and do not know where to start.

Therefore, local colleges and universities should organize personnel to go to the countryside for relevant research, and understand the specific needs of farmers for agricultural information to summarize the results of the survey into a report, and then to collect and collate relevant information to provide farmers with the agricultural information they really need. For example, the relevant regulations and policies of the state on agriculture can be printed into leaflets or pamphlets, which can be distributed to farmers in need. It can also make use of the convenience of academic resources of colleges and universities to download some relevant agricultural science and technology videos from foreign websites, then translate them into Chinese and distribute them to farmers by CD-ROM, or organize exhibition activities, so that farmers can better understand the most advanced agricultural technology in the world.

Moreover, local colleges and universities should use their own library collection resources to help and support the surrounding countryside. For example, they can cooperate with libraries at all levels of counties, townships and villages, and farmers' bookstores to realize library resources sharing, and farmers can borrow books from university libraries, so as to learn agricultural knowledge and enrich cultural life. This way has many advantages over donating books.

First, two-way communication has been strengthened.Donations are usually one-way. Organizations at all levels do not conduct detailed investigation before making book donations to 
rural areas, and they do not know what is the most urgent book needs of local farmers. However, book sharing gives farmers the right to choose freely, and farmers can choose the books they need independently, and with the update of university library collection, the resources they acquire are constantly updated. Moreover, farmers can communicate with colleges and universities to provide books for recommendation and purchase according to their own needs.

Secondly, waste is avoided. As mentioned above, if the specific needs of farmers for information cannot be truly understood, then donated books are likely to be left unattended. In this way, it is a waste of resources. The donors distribute books and other materials to the farmers, but maybe the farmers are not interested in these materials, or they cannot meet the needs of their production and life, thus causing a waste of information resources.

However, it is worth noting that in addition to providing material assistance, local colleges and universities should also invest a certain amount of human resources in the surrounding rural areas for information resources. For example, it is necessary to regularly exchange books for libraries at all levels of counties, townships and villages and rural library houses. For these libraries and rural library houses, colleges and universities should send special personnel to carry out business training for relevant management personnel to help them improve their business level, so as to better serve local farmers. In addition, the construction of reading environment and book classification methods also require colleges and universities to send professional personnel to train the responsible personnel of libraries at county, township and village levels and rural library.

Except for providing resources, a variety of reading promotion activities can be carried out to improve the interest of farmers and create a reading atmosphere. If we can cooperate with local media to carry out relevant activities, it will achieve better results, such as inviting local newspapers and TV stations to report on the activities.

\section{Provide relevant training}

There are two main ways to provide relevant training for farmers in agriculture, one is face-to-face teaching, the other is to provide network courses.

In fact, in the early 1980s, the central committee of the communist youth league proposed that college students carry out social practice of "San Xia Xiang" in their summer vacation and spare time. At the end of 1996, ten ministries, including the Propaganda Department, the Ministry of Agriculture, the Ministry of Culture of the Central Government, jointly issued the notice on carrying out "San Xia Xiang" activities of culture, science, technology and health. The next year, the "San Xia Xiang" activities were officially launched nationwide. The so-called "San Xia Xiang" actually refers to the three going to the countryside: culture, science and technology, and health. Undoubtedly, as the participants of "San Xia Xiang", colleges and universities throughout the country will inevitably provide a series of rural information services for local farmers, including face-to-face courses for farmers and the improvement of agricultural skills. Besides, governments at all levels actively organize farmers to enter universities for relevant studies, especially agricultural colleges and universities around the country, which will basically open short-term training classes for farmers. Through face-to-face exchanges, farmers can understand the most advanced agricultural science and technology and learn the most practical agricultural technology, which is of great benefit to their production and life.

The activities of college students going to the countryside can not only be limited to agricultural production, but also should be committed to improving the quality of rural cultural life. For example, local colleges and universities can use the library's audio-visual resources to show farmers films or operas. Teachers and students majoring in art or with artistic expertise can also prepare literary and artistic programs rich in rural elements, and hold literary and artistic evenings for local farmer friends, thereby enriching the cultural life of farmers and cultivating their artistic sentiment. Of course, teachers and students majoring in art should also look for traditional artists in the countryside and learn excellent folk art from these veteran artists, including folk art, handicraft and so on. While excavating local art, local colleges and universities should make use of their own conditions to digitize the collected rural art, which is conducive to the wider promotion and 
continuation of rural culture.

Apart from providing face-to-face teaching or training, local colleges and universities should also produce and provide corresponding network courses for farmers as far as possible. In view of the specific situation of farmers in Jilin Province, due to the climate and environment constraints, large-scale cultivation in winter can not be carried out, and most farmers in winter have a more comfortable leisure stage, so they have time conditions for more systematic learning of relevant knowledge. Therefore local colleges and universities can make video courses with rich content in agricultural technology according to the specific needs of local farmers.

However, the farmers in northeast China are relatively busy during the spring plowing period. In view of the potential problems of farmers in farming during this period, local universities can make corresponding micro courses to solve specific problems. Through the study of online courses, farmers can master corresponding agricultural skills. If they encounter specific problems, they can also seek the guidance of experts and scholars through the Internet. Compared with face-to-face training or teaching, online courses are undoubtedly more convenient for farmers to learn. Farmers can find the resources they need for specific problems, and using the Internet to spread agricultural knowledge has greatly reduced the cost.

\section{Create an agricultural information service network platform.}

Local colleges and universities can use the Internet to provide farmers with production, life-related information, such as WeChat, weibo, QQ and other Internet platforms can realize the real-time transmission and storage of information. Local colleges and universities can make full use of these platforms to push agricultural information to local farmers. For example, information that such as energy conservation, emission reduction and the increase of irrigation efficiency achieved through advanced science and technology can help build ecological agriculture and promote the sustainable development of rural areas.

At present, our country lacks a targeted network platform in the services involving farmer information, which should be further promoted. When building the agricultural information service network platform, the practical needs of rural population should be taken into account first, which needs extensive investigation in rural areas to get a thorough understanding of the specific information needs of farmers in production and life. Only when we have a deep understanding of the needs of farmers can we create a network platform that truly serves them.

In the process of designing agricultural information service network platform, we should pay attention to simplicity. The cultural level of farmers is generally not high. If the operation steps or modules are too complex, it will lose practicability to a certain extent. Moreover, for farmers, the practical demand is greater than the aesthetic demand, so the operation interface of the network platform must be clear as the main principle. In the process of promoting the platform, the relevant personnel in charge of local colleges and universities should go into the field, carefully guide farmers to use the agricultural information service network platform, and collect specific suggestions and opinions from farmers, so as to further enhance the convenience of the network platform. Therefore, in the process of operation and maintenance of the network platform, we must pay attention to the two-way communication and exchange with farmers.

The information content provided by agricultural information service network platform must follow a main idea, that is, pay attention to the universality and pertinence.The so-called universality means that the information service provided by the platform should cover all aspects of farmers' production and life as far as possible. For example, in the field of crop planting, it should provide professional and systematic services in the fields of crop selection, breeding, fertilization and harvesting. In addition to agricultural production, attention should also be paid to the daily life of farmers to provide them with some health and entertainment information. The pertinence requirement refers to that the content provided by the agricultural information service network platform must meet the basic needs of local farmers. If the aquaculture industry in the region is relatively developed, the platform shall provide relevant information on aquaculture. By the same token, if the farmers in this region plant grain crops for the main business, then according to its 
specific food crops to select the corresponding agricultural information to release on the platform. For example, most of the crops in Northeast China are corn, rice and soybeans, then information provided by the network platform is given priority to with these crops. If we want to popularize some new varieties of cash crops, we should also consider whether they are suitable for farming in rural areas.

\section{Developing tourism resources}

In 2017 government work report, Premier Li Keqiang emphasized to "build rural villages with both modern civilization and beautiful scenery", and called for "farmland rotation and reform of fallow cultivation". It can be seen that building a new socialist countryside in the 21st century should not only focus on the sustainable development of resources, but also step up efforts to explore tourism resources.

As for Jilin Province, it is located in heartland of Northeast China. The three directions of North, South and West are Heilongjiang Province, Liaoning Province and Inner Mongolia Autonomous Region respectively. Its eastern part is border on Russia, the southeast part is across the river from Korea. With the White Mountain and black soil, Jilin is vast and magnificent and has abundant tourism resources. The main mountains in Jilin province are big Black Mountain, Zhang Guangcai ridge, hadaling, Lao Ling, Mudan ridge and so on. There are 265,500 hectares of rivers and lakes in Jilin Province, and 1648 rivers with an area of more than 20 square kilometers. The main lakes are Changbai Mountain Tianchi, Songhua Lake, Yan Ming Lake, Chagan Lake and moon bubble. But except for Changbai Mountain, there are few 5A scenic spots in the province. And the effect of tourism development is very obvious to pull the economy, so universities have the obligation and ability to help local governments at all levels to develop tourism resources. Compared with traditional agriculture, the economic benefits brought by tourism resources are quite objective.

It is particularly worth mentioning that in the northwest region of Jilin Province, such as Songyuan and Baicheng have rich wetland resources and aquatic resources, in which the fish, shrimp and crab with excellent quality and taste first-class. But many of these agricultural and sideline products are "kept in the deep boudoir that people do not know" and do not form a complete industrial chain. Most of people who go fishing and play are residents of nearby towns.

At present, there are six 5A scenic spots in Jilin province, four of which are located in Changchun, capital of Jilin province. In fact, some tourism resources in Jilin Province are of great ornamental value, but they have not been fully exploited due to remote geographical location and other reasons. For example, the Jilin Qian'an Mud Forest National Geological Park, 40 kilometers southwest of Qian'an County, Songyuan City, covers two towns, Suozi Town and Dabusu Town, with a total area of 1.1 million square kilometers. The main landscape of the Geopark is the erosion geology and landform, which is changeable and graceful affected by wind and rain and so on. Many photographers come to take pictures of the beautiful scenery of mud forest. But apart from attracting small groups such as photography and geological enthusiasts, most of the residents in Jilin Province have never heard of the park, and few have visited it. It can be seen that for rural areas, how to develop tourism resources is a question worth thinking about.

Local colleges and universities can provide information services for rural areas in this respect. For example, media majors can use the Internet to help rural areas to publicize tourism resources, art majors can design related cultural and creative products, and marketing majors can plan marketing plans, etc. In the construction of tourism resources in rural areas, the lack of material assistance is not the most serious, and the funding of governments at all levels can complete the basic construction, then the lack of tourism resources in rural areas is the promotion of the non-material level. Local colleges and universities should consciously play their own advantages, and use information-based means to make its due contribution to developing the rural areas and raising farmers' economic income. Local colleges and universities can try to speed up the development of rural tourism resources by means of scientific research projects and college students' entrepreneurship training, so as to achieve mutual benefit. 


\section{Conclusion}

To sum up, under the current background of the times, rural informatization service construction is in urgent need of promotion, while local colleges and universities have the responsibility and obligation to join in the rural information service construction, give play to their own advantages to guide rural information, and use their own resources to study the specific application of rural information. As a large agricultural country, "three rural" issues have always been related to economic development and social stability in China, and local colleges and universities should shoulder the heavy burden and make due efforts to promote the construction of rural information.

For farmers, books, audio-visual materials and other materials provided by local colleges and universities, as well as organized lectures, evening parties and other activities can not only improve the agricultural production efficiency of farmers, but also enrich their cultural life. Using the Internet to provide information services for farmers is conducive to the two-way communication between local universities and farmers. In addition to developing agriculture, local rural areas should also actively develop tourism resources, and local colleges and universities can assist relevant regions in information in this field.

It is worth noting that provide information services for rural areas is also very helpful to the self-construction of colleges and universities. Teachers and students in colleges and universities can plan scientific research projects and innovate entrepreneurship projects according to the existing problems in rural areas, thereby improving the level of research, and applying theoretical knowledge to actual production and life. Therefore, in addition to agricultural and forestry colleges and universities, colleges and universities offering arts and economics majors should also actively participate in rural information services.

\section{Acknowledgement}

This paper is from the scientific research project "Research on the service model of farmers' information in the process of urbanization", of the 13th Five-Year Plan of Jilin Provincial Education Department in 2017, and the project number is: JJKH20170004KJ.

\section{References}

[1] Zhang Xudong. Research on Information Service Provided by University Libraries for New Rural Construction [J]. Heilongjiang Science and Technology Information, 2012 (23).

[2] Zhao Yingchun. The role of University Libraries in the new rural information construction in the era of big data [J]. Modern Agricultural Science and Technology, 2015 (16).

[3] Wu Zhigang, Xu Fuyin, Zhang Xuebo. Study on Architecture and Resource Application Effect of the Network Training Platform for Village \& Town Spatial Planning [J]. China Educational Technology, 2010 (06).

[4] Li Jihong. Cultivation of Teachers' Professional Values of Normal University Students: Connotation, Value and Strategy [J]. Theory and Practice of Education, 2010 (13).

[5] Chenxin. Status and Problem Analysis of Internationalization Development of Local University [J]. Meitan Higher Education, 2009 (06). 